\title{
Corpos em manifesto performático urbano
}

\author{
João Vítor Ferreira Nunes ${ }^{1}$
}

Submetido em: 17/02/2021

Aprovado em: 18/03/2021

DOI: $10.5965 / 2358092525252021232$

1. Mestra pelo Programa de Pós-graduação em Artes Cênicas da Universidade Federal do Rio Grande do Norte (PPGArC/UFRN). Doutoranda no Programa de Pós-graduação em Teatro da Universidade do Estado de Santa Catarina (PPGT/UDESC). E-mail: joãovitormulatto@gmail.com. 


\section{RESUMO}

Através deste artigo, pretendeu-se discutir acerca das teorias e noções de gênero, partindo da perspectiva da pensadora estadunidense Judith Butler (1990a; 2019b), de como as estruturas patriarcais são fortemente reproduzidas em contexto social, sobretudo por indivíduos que se encontram presos aos padrões culturalmente impostos pela heteronormatividade compulsória. Haja vista esses rituais de passagem (GENNEP, 2011) e rituais de crise de vida (TURNER, 2005), a artista-pesquisadora, proponente desta comunicação, em parceria com o Grupo de Pesquisa e Extensão Cruor Arte Contemporânea da UFRN e Homens Libertem-se, levou às ruas um manifesto para contestar e refletir acerca das imposições patriarcais, contribuindo a seu modo, para subverter essa realidade por meio da Performance Urbana. Por fim, ergue-se, desta maneira, um tripé de interlocução entre noções de gênero, padrões de comportamento e atos performáticos urbanos em coralidade.

Palavras-chave: noções e teorias de gênero, nefasta virilidade masculina, performance urbana. 


\section{ABSTRACT}

Through this article, it was intended to discuss about gender theories and notions, from the perspective of the American thinker Judith Butler (1990a; 2019b), of how patriarchal structures are strongly reproduced in a social context, especially by individuals who are imprisoned by standards culturally imposed by compulsory heteronormativity. Considering these passage rituals (GENNEP, 2011) and life crisis rituals (TURNER, 2005), the artist-researcher, proponent of this communication, in partnership with the Research and Extension Group Cruor Arte Contemporânea at UFRN and Man Free Themselves, he took to the streets a manifesto to contest and reflect on the patriarchal impositions, contributing in his own way, to subvert this reality through Urban Performance. Finally, in this way, a tripod for dialogue between gender notions, behavior patterns and urban performance acts in chorality is erected.

Keywords: gender notions and theories, nefarious male virility, urban performance. 


\title{
INTRODUUÇÃO - BREVE APRESSENTAÇÃO DO CONTEÚDO E DAS BASES TEÓRICAS
}

São as experiências do cotidiano que nos levam de um estado físico e/ou emocional para outro, segundo Arnold van Gennep (2011), e todo esse conjunto de afetações ocasionadas pela vida podem ser utilizados como repertório na seara das artes da cena. Este é um processo cíclico, e fora denominado também pelo o antropólogo britânico, Victor Turner, em seu livro Floresta de Símbolos (2005), como rituais de crises de vida, e acerca disso, o autor afirma:

\begin{abstract}
Nas sociedades mais simples do mundo, e também em muitas sociedades civilizadas existe uma série de cerimônias ou rituais destinados a marcar a transição de uma fase da vida ou do status social para outra. Estas cerimônias de crises não dizem respeito apenas ao indivíduo que ocupa o lugar central nelas, mas também marcam mudanças nas relações de todas as pessoas ligadas a ele por laços de sangue (TURNER, 2005, p. 35 apud NUNES, 2019a, p. 12).
\end{abstract}

Fora em contexto de graduação em Teatro na Universidade Federal do Rio Grande do Norte (UFRN), entre 2013 a 2016, que passei a ocupar os porões de minhas his(es)tórias, e perceber que tive uma infância talhada numa violência social e cultural acerca do gênero, sobretudo ao que se refere à heteronormatividade compulsória. Olhar para o passado e perceber que os homens que me cercavam queriam introjetar os ideários de masculinidade em mim, por afirmarem que algo de feminino em mim se aflorava a cada dia, me fez perceber que meu corpo era dissidente naquele contexto. Essa dura realidade passou a me assombrar dia após dia, e compreendi em tempos atuais que a homofobia é estrutural, cultural e assola inúmeras vidas, fazendo com que indivíduos, que estão distantes dos padrões esperados pela sociedade, fiquem regressos nos porões de suas obscuridades. 
Ao longo desse acampar em minha dimensão interior, constatei que da infância à adolescência, havia experienciado situações de violência por ser quem eu era; um ser feminino - na visão dos sujeitos que me rodeavam -, e por ser feminino, ou seja, fora do padrão imposto, fui levada à força para protagonizar situações de violência física, emocional e psicológica, tendo meu corpo utilizado, muitas vezes e em diferentes momentos e espaços, como modelo negativo frente às pessoas que compunham meu lar. Os agressores, tendo em vista que o principal deles era o meu pai, estavam presos a esses padrões culturais, onde supervalorizavam a virilidade masculina, enquanto a feminina era colocada em um traçado de inferioridade. Esses momentos nefastos duraram o tempo suficiente para que eu sofresse violências desenfreadas e passasse a carregar em meu corpo marcas da normatividade hegemônica. Ou seja, duras memórias foram se estruturando em minha cabeça, feito um jogo de peças.

Ao chegar no curso de graduação em Teatro da Universidade Federal do Rio Grande do Norte (UFRN), essas memórias movediças foram postas à mesa, a fim de serem devoradas. Me dediquei aos estudos e entendimentos das violências de gênero e aos padrões culturalmente impostos, e todo esse conjunto de materiais foi sendo utilizado por mim nas práticas performáticas, cujo objetivo sempre foi olhar para o passado e contestar os modos pelos quais buscam anular e engessam as performatividades $\mathrm{d} /$ nos corpos.

A partir de pesquisas teórico-práticas, enquanto artista-pesquisadora, queria verdejar os solos das artes da cena, bem como conscientizar o público acerca dos temas expostos, ampliando as camadas das artes com atos políticos. Faz-se mister explicitar que os estudos acerca dos corpos e memórias foram sendo ampliados gradualmente, me levando à realização de pesquisas de mestrado no Programa de Pós-graduação em Artes Cênicas da Universidade Federal do Rio Grande do Norte (PPGArC UFRN) e de doutorado no Programa de Pós-graduação em Teatro da Universidade do Estado de Santa Catarina (PPGT UDESC). 
Os mencionados temas contribuíram demasiadamente para os entendimentos acerca dos corpos, padrões de comportamento, acumulações históricas e atos performáticos urbanos. A partir disso, compreendemos que,

Nos últimos anos, o argumento de que o sexo, o gênero e a heterossexualidade são produtos históricos, combinados e reificados como naturais ao longo do tempo, recebeu uma atenção considerável da crítica, não só de Michel Foucault, mas também de Monique Wittig, historiadores gays, e vários antropólogos culturais e psicólogos sociais. Essas teorias, no entanto, ainda parecem carecer de recursos críticos para pensar de forma radical a sedimentação histórica da sexualidade, bem como as construções relacionadas ao sexo, se não definem ou descrevem o modo como essas construções são cotidianamente produzidas, reproduzidas e sustentadas no campo dos corpos (BUTLER, 1990a, p. 09).

Há décadas, padrões de comportamento e estereótipos foram criados sob a figura masculina e feminina, e, ao longo do tempo, foram sendo naturalizados. Todas essas construções sociais não foram cultivadas apenas em uma sociedade ou grupos específicos, mas sim em todas as culturas, cada qual, a partir de sua realidade. Com isto, tornou-se cultural cultuar a figura masculina, enquanto a feminina era rebaixada, colocada em espaços de subalternidade, segundo Gayatri C. Spivak², especificamente as mulheres negras. Ao longo desse culto aos homens e sua virilidade, os indivíduos foram postos em pedestais - metaforicamente falando -, a fim de serem vangloriados, adorados, idolatrados. De antemão, a virilidade heteronormativa e compulsória encontra-se arraigada, e é reproduzida por inúmeros indivíduos. Para onde olhamos, avistamos no horizonte resquícios de uma educação cisgênera, que busca detur-

2. Aos que se interessarem por obras acerca da subalternidade, consultar: SPIVAK, Gayatri C. Pode o subalterno falar? 2014. 
par aquelas pessoas que estão distantes das normas hegemônicas, as quais segregam corpos, dando-lhes títulos de corpos dissidentes ou abjetos.

Para reiterar vocês, leitoras/es, de alguns rituais de crises de vida, abarco neste artigo mais um argumento do antropólogo Turner, onde nos apresenta diferentes tipos de educação que alguns indivíduos tiveram comparado a outros.

Embora tanto os meninos quanto as meninas passem por cerimônias de iniciação, a forma e o propósito das cerimônias diferem enormemente em cada caso. Os meninos, por exemplo, são circuncidados, mas não é praticada a clitoridectomia nas meninas. Os meninos são iniciados coletivamente; as meninas, individualmente. Os meninos são iniciados antes da puberdade; as meninas, logo no início da mesma. O principal objetivo da iniciação dos meninos é inculcar-lhes valores tribais, habilidades da caça e instrução sexual; o da iniciação das meninas é prepará-las para o casamento, que, na maioria dos casos, se segue imediatamente a esta iniciação. Os meninos são isolados e ensinados na floresta; uma cabana de palha é construída na própria aldeia para as meninas. Os principais pontos a serem notados, no entanto, são: o contraste entre a natureza coletiva da cerimônia dos meninos com o tratamento individual dado às meninas (TURNER, 2005, p. 36 apud NUNES, 2019a, p. 13).

Virginie Despentes, por sua vez, em Teoria King Kong(2016), nos apresenta outra perspectiva desses padrões de comportamento alimentado e reproduzidos por homens, dizendo:

Ser um homem de verdade - o que isso exige? Repressão das emoções. Calar sua sensibilidade. Ter vergonha de sua delicadeza, de sua vulnerabilidade. Abandonar a infância de modo brutal e definitivo: os homens-criança não possuem boa reputação. Ficar angustiado pelo 
tamanho do seu pinto. Saber fazer as mulheres gozarem sem que elas mesmas saibam ou queiram the indicar como. Não dar sinais de fraqueza. Amordaçar a sensualidade. Vestir-se com as cores discretas, usar sempre os mesmos sapatos grosseiros, nunca brincar com os cabelos, não usar muitas jóias, nenhuma maquiagem. Sempre dar o primeiro passo. Não possuir nenhuma cultura sexual para melhorar seu orgasmo. Não saber pedir ajuda. Ter que ser valente, mesmo sem ter nenhuma vontade. Valorizar a força, seja qual for seu caráter. Mostrar agressividade. Possuir um acesso restrito à paternidade. Ter sucesso social para poder pagar as melhores mulheres. Morrer de medo de sua homossexualidade, porque um homem de verdade não deve nunca ser penetrado. Não brincar de boneca quando pequeno, contentar-se com carrinhos e armas de plástico muito feios. Não cuidar muito do seu próprio corpo. Submeter-se à brutalidade de outros homens sem reclamar. Saber se defender, mesmo sendo doce. Ser privado de sua feminilidade, como as mulheres se privam de sua virilidade, não em função das necessidades de uma situação ou de um caráter individual, mas em função daquilo que o corpo coletivo exige. De tal maneira que as mulheres ofereçam sempre seus filhos para a guerra e que os homens aceitem se deixar matar para proteger os interesses de três ou quatro cretinos da visão curta (DESPENTES, 2016, p. 23-24 apud NUNES, 2019a, p. 15).

Assim como Turner, Despentes nos dá exemplos de padrões de comportamentos voltados à figura masculina e feminina, e, ao que me parece, para que os meninos se tornem sujeitos viris, cortantes, eles passam por uma educação mais livre, em alguns aspectos, e em outros, têm sua liberdade violada. Turner nos fala sobre a tribo Ndembu, África Central, enquanto Despentes nos fala sobre sua vivência em solo europeu, na França.

Tecendo comparativos entre os argumentos presentes nas duas obras, me vi diante de minha realidade, onde eu era trei- 
nada para ser livre, mas, ao mesmo tempo, presa, e essa prisão social me levava ao encontro a um fracasso emocional, a qual me distanciava, cada vez mais, de quem eu realmente era, ou gostaria de ter sido.

Em todo este material, venho a apresentar meus estudos, teóricos e práticos, tendo como plataforma a Performance para a realização de comunicações performáticas, o qual vim enlaçando as noções e teorias de gênero. Busco, não apenas por meio deste compilado de escritos, descristalizar a normatividade com alguns argumentos, me colocando fora do padrão social esperado, como também pretendo fruir como ocorreu a ação performática urbana realizada junto ao Grupo de Pesquisa e Extensão Cruor Arte Contemporânea, da cidade de Natal, RN. Lançarei mão do processo; de sua confabulação ao ato final.

\section{DESENVOLVIMENTO - DA CONFABU LAÇÃO AO ATO PERFORMÁTICO URBANO}

Acredito que seja de grande relevância para o cenário dos estudos da performance no Brasil apresentar resultados de práticas performáticas que foram estruturadas em âmbito acadêmico e realizadas em espaços urbanos. Neste artigo, exponho como aconteceu o manifesto performático urbano intitulado SE NÃO HOJE, QUANDO?, desde sua confabulação ao ato final, tendo em vista o seu impacto em contexto social. A ação fora realizada pelos performers do Grupo de Pesquisa e Extensão Cruor Arte Contemporânea, da Universidade Federal do Rio Grande do Norte (UFRN), coordenado pela professora Doutora Nara Graça Salles ${ }^{3}$.

A escolha do tema nos veio à mente quando conhecemos o projeto Homens Libertem-se, e sua repercussão na cidade de Nova lorque. Trata-se de iniciativas de pesquisadoras com estudos teóricos e práticos, visando conscientizar homens dessa compulsão pela heteronormatividade. Com as pesquisas, buscam

3. Atualmente, é professora da Universidade Federal de Pelotas (UFPel). 
contribuir para a desconstrução de alguns padrões de comportamento masculino, principalmente aqueles que envolvem violência contra corpos e seus aprisionamentos. Nós, enquanto performers do Cruor, por carregarmos em nossos corpos algumas marcas dessas violências sofridas em nosso lar, decidimos trabalhar com conteúdos que estavam próximos a nós, como as memórias da infância à adolescência, principalmente aquelas que vivenciamos em alguma medida, e que se assemelhavam às desigualdades sofridas por termos identidades de gênero ou orientação sexual diferente dos nossos agressores.

A partir da problemática levantada, tínhamos a intenção de sistematizar um conjunto de ações que viessem a conscientizar homens, descristalizando, desta maneira, os padrões de comportamento e estereótipos que estavam arraigados e sendo reproduzidos. Todavia, não queríamos nos prender, mais uma vez, à universidade. Gostaríamos de levar o trabalho prático para fora da instituição, para então ampliar as camadas sobre o tema proposto, bem como o ato. Fizemos isto por acreditar que seja de suma relevância que a sociedade participe, como um todo, de pesquisas e projetos que são realizados em âmbito institucional, e se sintam parte das atividades.

Ir às ruas com arte é uma maneira de estimular o consumo de outrem, e possibilitar que essas pessoas sejam atravessadas por novas maneiras de se pensar. Este foi apenas mais um dos motivos que nos levaram a realizar o manifesto nas ruas da cidade de Natal, Rio Grande do Norte. Contudo, antes de rumarmos para às ruas, foi preciso estruturar, por completo, a ação, definindo os espaços a serem ocupados, o público alvo a ser atingido e os objetivos a serem alcançados.

Quanto ao público alvo, definimos em reunião que seriam os homens, fossem eles adolescentes ou adultos; tendo em vista que são indivíduos do gênero masculino que mais reproduzem os padrões de comportamento por estarem presos a eles. Os objetivos que tínhamos, era causar a fruição da performance e conscientizar o público a partir do tema proposto: violência de gênero em contexto social. Com relação aos espaços, decidimos 
que aconteceriam nos bairros de Capim Macio e Ponta Negra, por serem mais populosos devido o número de turistas.

A partir da definição da problemática, dos objetivos a serem atingidos, do público alvo e dos espaços a serem ocupados, nos dedicamos a pensar o que, e como gostaríamos de transmitir as mensagens. Chegamos à conclusão de que embora nossos corpos já causassem um impacto nas ruas devido à coralidade, ainda não seria o suficiente. Com intenção de fazer uso da voz, entoando canções, poemas e frases, realizamos novas imersões nos porões de nossas memórias e reunimos novos materiais. Eu, particularmente, fiz uma busca no campo de minha consciência, e apresentei ao grupo um material similar ao seguinte, com intenção de que falássemos em coro, característica essa de ação em coralidade:

Quem disse que eu não posso broxar? Que não posso falir, ser frágil e sensível? Que não posso chorar, vestir peças de roupas cor de rosa e sentir prazer pelo meu ânus? Eu tenho o direito de explorar o meu próprio corpo e me alegrar do jeito que ele é, com frequência, seja um falo pequeno ou minúsculo. Eu tenho o direito de não ser violento com o próximo e abraçá-lo não apenas quando o meu time fizer um gol, mas também quando me sentir à vontade. Eu posso cuidar de minha pele, inclusive de meu cabelo e de minhas unhas. Posso frequentar salões de beleza e inclusive trabalhar em um como cabeleireiro ou manicure. Posso cuidar da casa e dos filhos, enquanto minha esposa trabalha e sustenta o lar. Tenho total direito, inclusive, de não gostar de futebol e dizer que há homens bonitos, e elogiá-los quando quiser, enaltecendo a sua beleza. E, mais do que tudo isso, eu posso e devo respeitar todas as mulheres existentes (grifos da autora, 2021).

As demais componentes do Cruor levaram seus materiais, como canções, mantras, poemas e algumas dinâmicas que faríamos nas ruas a partir das ações físicas. Além de querer passar 
mensagens de conscientização sobre a compulsão pela heteronormatividade, queríamos deixar algo com os homens que conosco cruzassem.

Uma das componentes do grupo de pesquisa que já trabaIhava com figurino, Jessica Cerejeiras ${ }^{4}$, propôs que confeccionássemos algumas saias com o slogan do projeto Homens Libertemse. Assim, no ateliê do Cruor, ainda na UFRN, pegamos os tecidos brancos que tínhamos, os potes de tinta vermelha, tesouras, agulhas e linhas, e partimos para os trabalhos manuais. Por cerca de três dias, nos dedicamos a confeccionar as saias, e foi assim que fizemos o total de 5 , a fim de trocar as peças com os sujeitos que conosco cruzassem, para então estimular que os mesmos a utilizassem em seu cotidiano, pois, pudemos perceber que há um grande número de indivíduos que são alimentados pelo achismo de que a saia é uma peça de roupa somente feminina, enquanto as bermudas e calças ficaram marcadas como roupas masculinas. E eis um registro fotográfico da nossa produção.

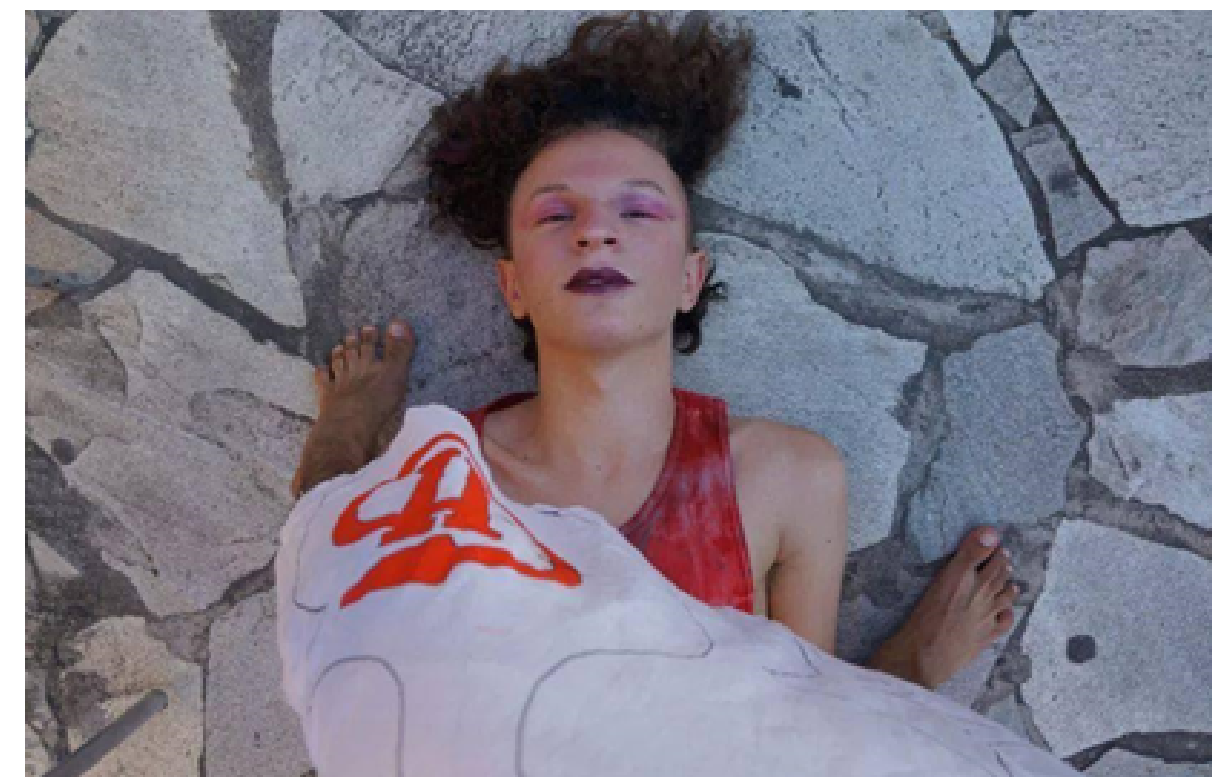

Figura 1: Performers: Pedro Fasanaro e João Vítor Mulato Local Avenida Roberto Freire, em Natal (RN)

Fonte: Arquivo pessoal da artista-pesquisadora 
Com os materiais reunidos e o motim formado, nos lançamos para as ruas da cidade, para os bairros de Capim Macio e Ponta Negra. Iniciamos a ação portando maquiagem, as saias e descalças, desvelando a performatividade de gênero que externávamos externando naquela época e momento ${ }^{5}$. Saímos caminhando pela avenida principal, Roberto Freire, cruzando faróis, dançando e cantando. Havia gritos nossos em todos os espaços, e cavalgamos todas as encruzilhadas. De forma lúdica, ocupamos os bancos das praças, os galhos das árvores e o chão. O colo das pessoas, sobretudo dos homens, e abraçamos a todos. Enquanto uns retribuíam os abraços, outros corriam com expressões de estranhamento. Por mais que tivéssemos em mente que os corpos alheios são territórios desconhecidos, e que requer licença, ainda assim nos permitimos realizar trocas com contatos físicos, pois,

Na rua ou no ônibus, o ato se torna perigoso, se realizado, porque simplesmente não há convenções teatrais delineando o caráter puramente imaginário do ato; não existe, na rua ou no ônibus, qualquer presunção de que 0 ato é diferente da realidade. O efeito perturbador do ato deriva da ausência de convenções que facilitem essa demarcação (BUTLER, 1990a, p. 12).

A cada cruzamento, novos grupos de pessoas paravam para nos observar, e alguns deles entravam em nossos jogos, se permitindo performar. Todavia, notamos que, quando falávamos algo que a eles incomodasse, paravam de performar e se dedicavam a pensar sobre os próprios conceitos, dizendo frases como: elas estão falando de mim, ou, caramba, esse sou eu, e ainda, eu estou envergonhado!!! Notamos que quando homens estavam acompanhados de suas namoradas ou esposas, e até de suas mães, eles ficavam envergonhados por reproduzirem o

\footnotetext{
5. Digo, "naquela época e momento", pelo fato de reconhecer que a todo instante as performatividades de gênero estão se modificando constantemente, conforme os rituais de passagem, inclusive em nós LGBTQIAS+.
} 
machismo e não terem despertado para tal. Saliento que, não estávamos postas nas ruas para envergonhá-los, nem tão pouco colocar sobre eles juízos de valor. Queríamos abrir caminhos para uma reflexão, e muitos deles refletiram sobre seus lugares de privilégio por serem homens. Conseguimos, desta forma, colocá-los para

[...] refletir a possibilidade de subverter as noções naturalizadas e reificadas do gênero que dão suporte à hegemonia masculina e ao poder heterossexista, para criar problemas de gênero não por meio de estratégias que representem um além utópico, mas da mobilização, da confusão subversiva e da proliferação precisamente daquelas categorias constitutivas que buscam manter o gênero em seu lugar, a posar como ilusões fundadoras da identidade (BUTLER, 2019b, p. 70).

Por cerca de três dias consecutivos, das 14:00h às 17:00h, as ações aconteceram no Praia Shopping, na Feira de Artesanato de Natal, na Avenida Roberto Freire, no Branco do Brasil, nas Praças Públicas e suas árvores. Contudo, ao fim, reconhecemos que poderíamos ter ocupado mais espaços na cidade, ou ter performado em outros lugares, para então deixar nossas marcas nestes espaços, mas, chegamos à conclusão de que, ao mesmo tempo em que demarcamos territorialmente somente aqueles bairros, havia, constantemente, pessoas completamente diferentes. Com isto, pontuo que,

Tratando do contexto da troca, ficou posto [...] que era mais válido estabelecer contato com as pessoas que se colocavam enquanto público do que com as próprias bailarinas, visto que todas as dançantes já conheciam, parcialmente, os corpos umas das outras. [...] éramos também convidadas a nos adaptar não somente aos espaços, mas, principalmente, ao corpo alheio, respeitando os limites, as chegadas e as saídas, bem como suas recusas. Havia uma surpresa nas ruas, sobretudo 
nas pessoas, nos diferentes corpos. Algo mais autêntico e atravessador. Vale levar em consideração que os espectadores ao serem convidados a dançar ou, ao parar para nos observar dançando, abandonavam, parcialmente, o que estavam fazendo e nos acompanhavam, retroalimentando uma troca imensamente generosa. Emergindo danças mais pessoais (NUNES, 2019b, p. 129).

Richard Schechner afirma que "qualquer comportamento, evento, ação ou coisa pode ser estudado como se fosse performance, e analisando em termos de ação, comportamento, exibição" (SCHECHNER, 2003, p. 39), e com isso nos dedicamos a estudar o comportamento de alguns homens, sobretudo aqueles que expressam ações de masculinidade tóxica, seus conteúdos cisgêneros de dominação, os quais desembocam em atos violentos. Nos apropriamos de alguns desses comportamentos sociais e os transformamos em repertório, a partir de uma dinâmica idealizada pela performer Josie Pontes (RN). Estávamos em 5 pessoas, cada uma ditava algo que fosse relacionado ao tema, e, as demais componentes do grupo, uma a uma, se colocavam em cena, formando uma só imagem, como é estruturado o jogo da fotografia da Viola Spolin . Quando realizamos essa ação, já estávamos na praça da Feira de Artesanato, e percebemos que alguns homens estavam nos observando, e o fato deles pararem para nos observar foi importante, pois envolvia ações corporais que remetiam à violência, submissão e humilhações. $E$, antes que se dispersassem, tomamos a iniciativa de propor as trocar de roupas, e com isso, conseguimos arrecadar 2 bermudas e 1 calça jeans, e demos as saias confeccionadas por nós para que usassem dali em diante. As peças que conseguimos reunir nas três tardes, doamos para quem realmente necessitava de vestimenta, como pessoas carentes que estavam nos faróis ou em situações de rua. A imagem abaixo, é registro do Jogo da Fotografia, inspirado na metodologia teatral da Spolin. 


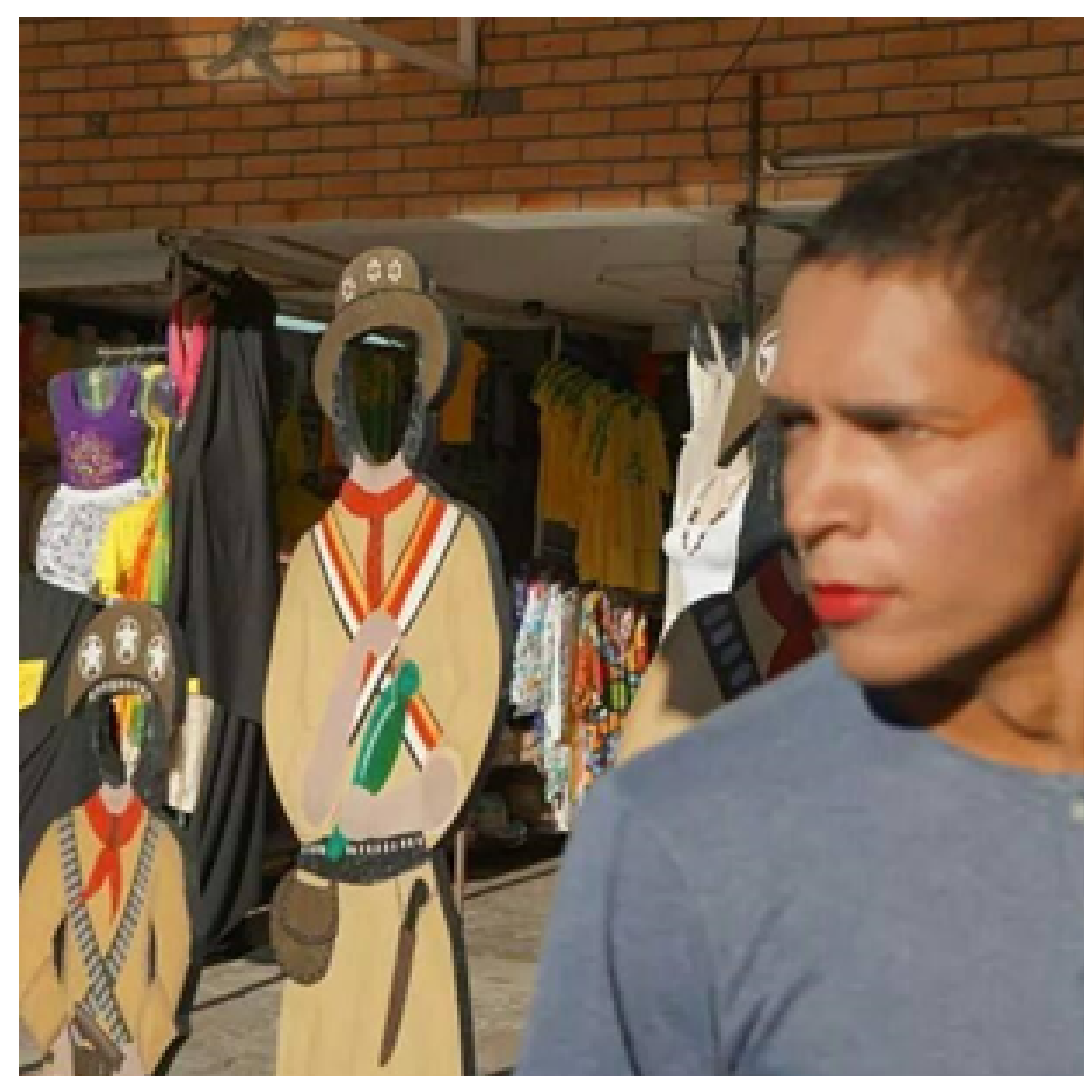

Figura: Performer João Vítor Mulato - Local: Feirinha de Artesanato de Natal (RN)

Fonte: Registro de Josie Pontes

Estudando materiais sobre performance, sobretudo aquelas que aconteceram em espaços urbanos, me deparei com os escritos da pesquisadora Bia Medeiros (UnB), e em seus artigos, ela versa sobre suas práticas, de como vem atravessando outros indivíduos com artes performáticas urbanas. Comumente, lidamos diariamente com registros fotográficos de performances já realizadas, contudo, devemos nos inteirar de que aquilo não é, em si, a performance, mas registros fotográficos das mesmas. Acerca disso, a pesquisadora Bia Medeiros nos diz que,

[...] fotografias não podem ser jamais consideradas performances, por mais fortes e envolventes que sejam, serão sempre registros, recortes de ações retiradas de seus contextos, arrancadas de seus sons e cheiros, serão 
registros, fragmentos de instantes desterritorializados. O tempo, elemento estético imprescindível da performance, foi desintegrado (MEDEIROS, 2005, p. 135).

A partir disso, o Aqui e Agora é algo que circunda o ato performático e, evidentemente a realização da performance torna-se mais potente no momento do ato, porém, compreendo que a escrita e a imagem (o relato e a fotografia) - visto que os reconheço como um percurso de traição por esquecermos inúmeras informações relevantes - é uma das maneiras de causar a fruição das práticas artísticas realizadas. Saliento, a partir de Bia Medeiros (2005), que os registros fotográficos presentes neste artigo não devem ser vistos como a performance em si, tendo em vista que ela foi muito maior do que aquilo que há relatado neste artigo, sobretudo seu impacto de conscientização acerca do tema. As fotografias que devem ser vistas como registros, lembranças, mas não como a performance urbana.

Quanto ao ato em coralidade, enxergamos que as ações físicas se tornam ainda mais potentes, vistas por nós como cardumes ao longo da empreitada, podendo ser reconhecida também em outros momentos como um só corpo, mesmo com tantas diferenças fenotípicas. Com a coralidade, temos a possibilidade de afinar laços e possibilitar que artistas se unam e criem grupos para causar fomento de artes urbanas. Com isso, fazer performance nos espaços não acadêmicos nos despertou amplo interesse em confabular novas ações, todavia, teríamos que repensar em outros temas e suas ações práticas.

A partir dessa iniciativa, conseguimos retirar aquilo que fora estruturado na academia para os espaços urbanos, possibilitando que outros indivíduos fossem atravessados com pensamentos sobre o tema proposto e, principalmente, com fazeres artísticos performáticos, como bem apresentado na imagem abaixo. 


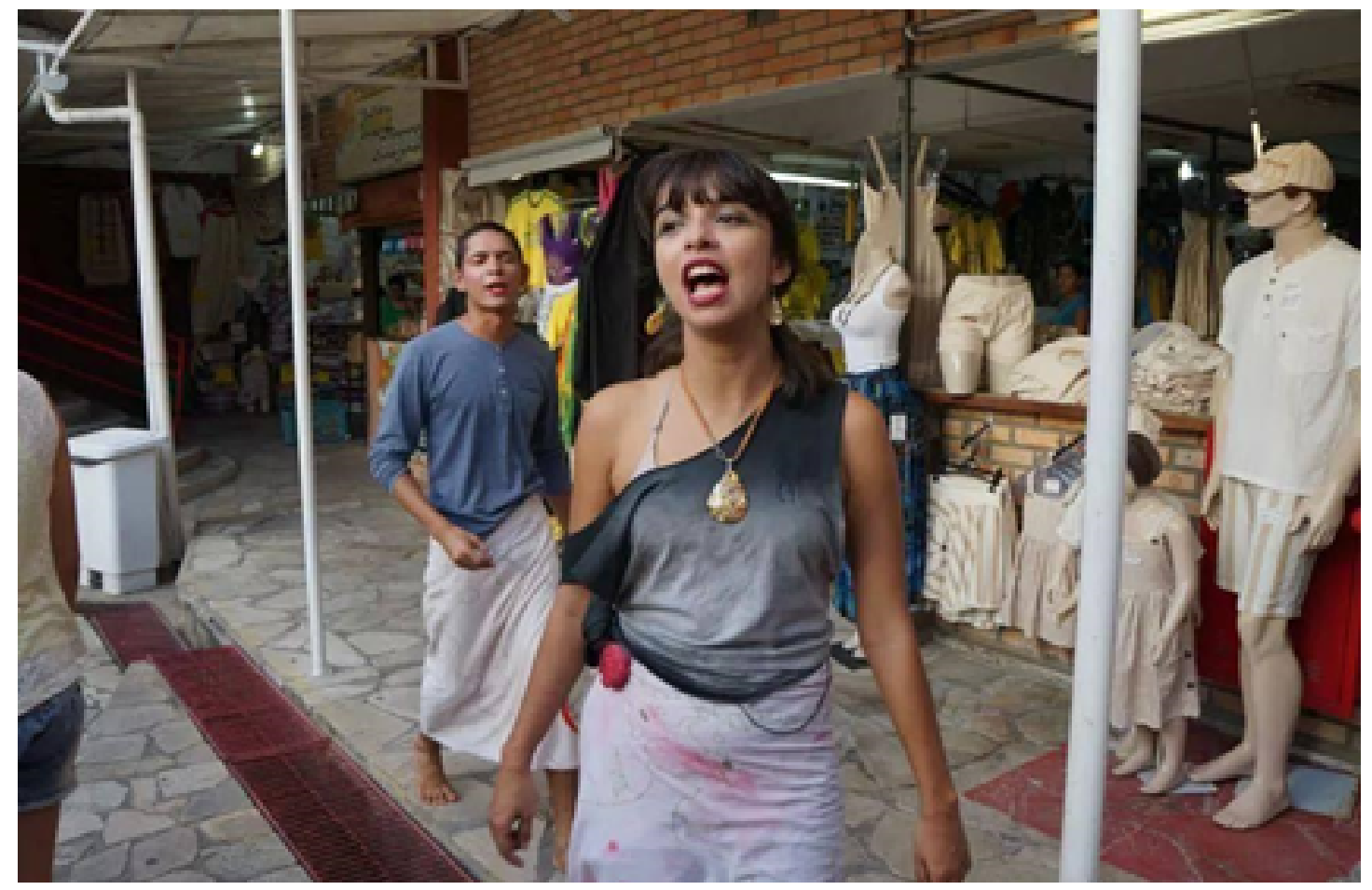

Figura: Performers Josie Pontes e João Vítor Mulato Local: Feirinha de Artesanato de Natal (RN)

Fonte: Registro de Pedro Fasanaro (RN)

\section{CONCLUSÃO - SE NÃO HOJE, QUANDO?}

Renato Cohen diz que "a performance é antes de tudo uma expressão cênica" (COHEN, 2002, p. 28), e ela, a meu ver, possui uma potência enriquecedora por não ter uma definição metodológica concreta. Com isso, foi possível que erguêssemos uma ação a partir das nossas memórias, coadunando com um tema tão pungente e que ocorre frequentemente em contexto social. No fim, percebemos que tínhamos um objetivo para além da fruição da arte, que era o fim pedagógico, conscientizador.

Reconheço a performance como um meio expressivo que pode ser ampliado de várias maneiras, e com teores políticos. Partindo dessa perspectiva, o título de nossa performance urbana, SE NÃO HOJE, QUANDO?, fora visto por nós como um gatiIho, um autoquestionamento sobre a iniciativa da realização do manifesto. E, enquanto pesquisadora, tenho caminhado contra os sistemas heteronormativos e compulsórios, realizando estu- 
dos que contribuam para o seu rompimento e sua descristalização, sobretudo aqueles que rotulam, limitam e aprisionam as pessoas e seus corpos.

Faz-se necessário nos colocarmos como artistas nas ruas, e ocuparmos não apenas as margens, mas também os centros, resistindo com trabalhos e manifestos artísticos para então atingirmos um número maior de indivíduos. Corpos, memórias e suas acumulações fizeram parte da ação performática, e transformamos, a meu ver, nossos corpos em um elemento essencial para compor as ruas.

Com a ação, notei que, da mesma maneira que as ruas nos deixaram marcas, nós também as deixamos marcadas. Entretanto, não marcamos apenas aqueles bairros, suas ruas e estabelecimentos, mas também as pessoas que conosco cruzaram, sobretudo os homens, sendo eles nosso público alvo. $\mathrm{O}$ corrente relato de experiência artística faz parte de minha pesquisa de doutorado, assim como de vida, e o fomento deste trabalho aponta quais caminhos sigo trafegando e ocupando enquanto artista e pesquisadora em Performance, sobretudo com ações urbanas em coralidade. 


\section{REFERÊNCIAS}

BUTLER, Judith. Performative Acts and Gender Constitution: An Essay in Phenomenology and Feminist Theory. In: (Ed) CASE, Sue-Ellen. Performing Feminisms, Feminist Critical Theory and Theatre. Baltimore: The John Hopkins Press: 1990a.

BUTLER, Judith. Problemas de Gênero: feminismo e subversão da identidade. 17. ed. Rio de Janeiro: Civilização Brasileira, 2019b.

COHEN, Renato. Performance como linguagem: criação de um tempo-espaço de experimentação. São Paulo: Editora Perspectiva, 2002.

DESPENTES, Virginie. Teoria King Kong. São Paulo: n -1 edições, 2016.

GENNEP, Arnold van. Os Ritos de Passagem. Rio de Janeiro, Petrópolis: Vozes, 2011.

MEDEIROS, Maria Beatriz de. Aisthesis: estética, comunicação e comunidades. Chapecó: Argos, 2005.

NUNES, João Vítor Ferreira. A força e a chuva feminina em um sertão bem masculino: imersão performática nos ritos de passagem de Bia Mulato pela mitodologia em arte / João Vítor Ferreira Nunes. 245 f. (Dissertação de Mestrado no PPGArC da UFRN), 2019a.

NUNES, João Vítor Ferreira. Dança Diaspórica: (des)ocupações como elemento de interação. Revista NUPEART, n. 22, p. 117-132. Florianópolis: UDESC, 2019b. 
SCHECHNER, Richard. O que é performance? Revista: $\mathbf{0}$ Percevejo, ano 11. Tradução Dandara, Rio de Janeiro: UNIRIO, 2003.

TURNER, Victor. Floresta de Símbolos: aspectos do ritual Ndembu. Niterói - RJ, 2005. 